\title{
INFLUENCE OF REPAIRING USING WELDED STEEL PATCHES ON STRUCTURAL INTEGRITY OF A HIGH PRESSURE GAS PIPELINE
}

The present paper deals with complex material properties of DN 300 pipeline from the section Olesna - Barchov. The work was aimed at experimental verification of the effect of welded-on cover patches on the pipeline integrity. Two types of welded-on cover patches were evaluated. In the first case, just a single patch - steel plate was welded into the pipeline wall, replacing the damaged area. A lack of root fusion was found by means of the NDT. In the second case, the primary patch welded into the wall was covered by an auxiliary patch welded over the first one. No imperfection of the weld integrity was shown in the second case. The experimental programme contained an evaluation of the resistance of the repaired section to 10000 pressure cycles induced by the inner water pressure at $R=0$ cycle load asymmetry and maximum pressure of 6.3 MPa. The effect of these repairs on the limit state of the pipeline was verified by means of hydrostatic burst test. The tests comprised the evaluation of fracture surface morphology.

Keywords: pipeline, hydrostatic burst test, repair patches, full scale test.

\section{Introduction}

As a result of a specific geographical position of the Czech Republic, relatively dense network of high pressure gas pipelines of up to $1400 \mathrm{~mm}$ diameter goes through its territory. The pipelines operate under different pressure conditions up to $8.4 \mathrm{MPa}$. Significant part of the pipelines is located inside of populated areas and so it has to be maintained at the highest safety level. Pipeline accidents in such areas would result in considerable material losses and, in the worst-case scenario, in injuries or loss of lives. Even at present, serious accidents of gas pipelines are not rare [1]. The last one in Czech Republic occurred and fortunately, there was no loss of human lives in this case [2].

To make the prediction of the behaviour of gas pipelines containing different defect types, it is necessary to verify experimentally, how the defects react on the pressure changes and how they reduce safety and reliability. Numerous recent experimental programmes have dealt with the loss of wall thickness due to area corrosion, pitting corrosion [3, 4] and, last but not the least, with the stress corrosion cracking, when a reliable detection by internal inspections may not be easy [5]. The pipe wall can also contain differently oriented cracks $[6,7]$ or dents [8] generated during the pipeline construction.

Previous regulations for the pipeline structures admitted repairs of some types of defects by overlapping. Such overlapping was carried out mostly under the reduced working pressure and caused several accidents in 2002. That is why the operation of this gas pipeline (in Argentina) was brought to a standstill and these repairs were examined by seven full scale hydrostatic burst tests [9]. The repair patches were of different type and size. It was clearly visible from the strain gauges records that the repairs had influenced substantially deformations of the tube wall.

In six cases, fracture occurred outside the patches. At the fracture of the body, the pressure was at least twice as big as the operational one.

\section{Experimental programme}

In case of unsatisfactory circumferential welds of gas pipelines in Czechoslovakia in the past, a specific repairing procedure was allowed to be performed. It consisted of three steps: (i) cutting out a rectangular part of the tube very close to the circumferential weld to be repaired, i.e. a kind of a "window", (ii) using this window for a repair of the main circumferential weld from the inside and (iii) welding the cut-off part (the plate) back into the tube wall, i.e. "closing" the window - Figure 1. However, the plate welding was not successful in all cases and overlapping had to be carried out - Figure 2.

\footnotetext{
* ' 'Jan Kec, ${ }^{1}$ Ivo Cerny, ${ }^{1}$ Jan Lustinec, ${ }^{2}$ Romana Pavelkova

${ }^{1}$ SVUM a.s., Celakovice, Czech Republic

${ }^{2}$ NET4GAS s.r.o., Praha, Czech Republic

E-mail: kec@svum.cz
} 


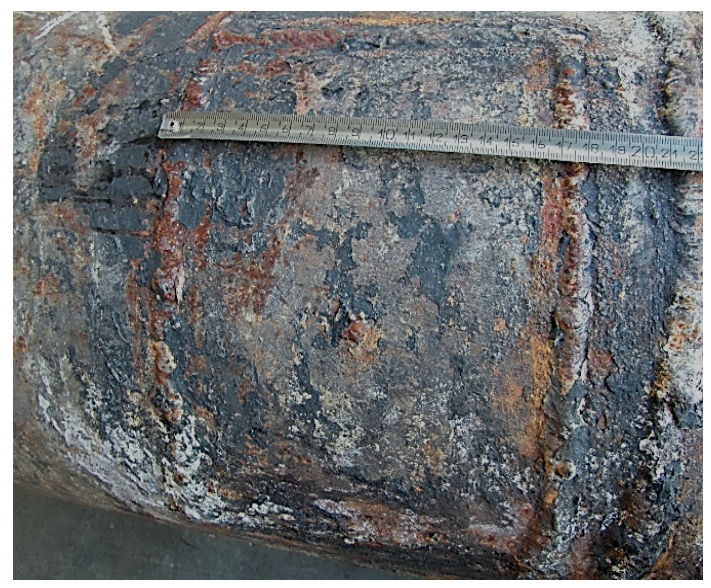

Figure 1 Steel repair-patch $A$

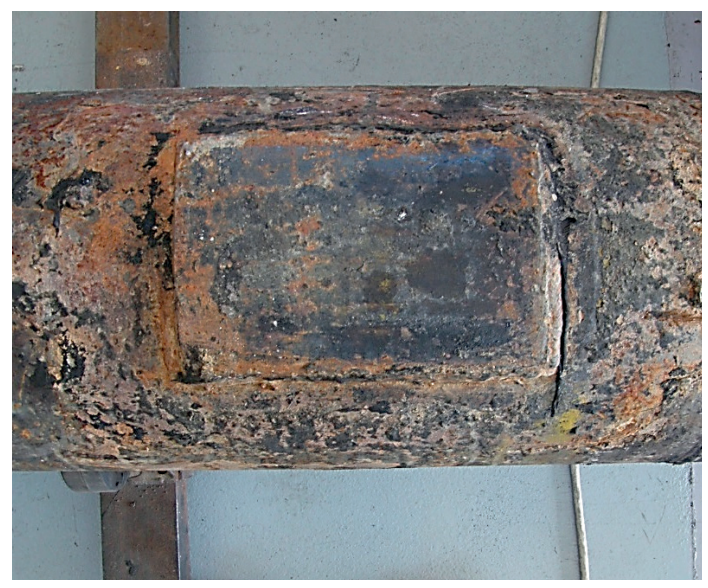

Figure 2 Steel repair-patch $B$

Table 1 Chemical composition

\begin{tabular}{cccccc}
\hline Elements & $\mathrm{C}$ & $\mathrm{Si}$ & $\mathrm{Mn}$ & $\mathrm{P}$ & $\mathrm{S}$ \\
\hline [wt. \%] & 0.12 & 0.29 & 0.35 & 0.013 & 0.024 \\
\hline
\end{tabular}

Table 2 Mechanical properties of the pipeline

\begin{tabular}{|c|c|c|c|c|}
\hline Direction of specimens & $\begin{array}{c}\sigma_{\mathrm{y}} \\
{[\mathrm{MPa}]}\end{array}$ & $\begin{array}{c}\sigma_{\text {uts }} \\
{[\mathrm{MPa}]}\end{array}$ & $\begin{array}{c}\text { Elong. } \\
{[\%]}\end{array}$ & $\begin{array}{c}\mathrm{CVN} 0{ }^{\circ} \mathrm{C} \\
{[\mathrm{J}]}\end{array}$ \\
\hline longitudinal & 299 & 424 & 31 & 81.8 \\
\hline circumferential & 271 & 432 & 26.5 & 160.8 \\
\hline
\end{tabular}

$\sigma_{y}$-yield stress, $\sigma_{u t s}{ }^{-}$ultimate tensile strength, Elong. - elongation after fracture, $\mathrm{CVN}$ - absorbed energy in Charpy impact test at temperature $0{ }^{\circ} \mathrm{C}$

Preliminary NDT (non-destructive testing) inspection showed the lack of root fusion in the whole length of repair patch A Figure 1. On the contrary, no imperfection of the weld integrity was found in the fillet weld in patch B (Figure 2) during the NDT inspection.

To evaluate the material properties, a ring was cut out from the pipeline. Chemical composition of the tube is summarized in Table 1. According to these data it can be said, that the tube material corresponds to the 11353 steel being commonly used for seamless tubes.

Investigations of microstructure and properties were carried out in longitudinal and circumferential direction. The base microstructure was ferrite-pearlite in both directions with uniform ferritic grains of the size 7.5 according to [10]. The pearlite colonies had typical lamellar morphology - Figure 3. A row-like structure was sometimes observed in the specimen centre.

Room temperature tensile tests of four specimens, two of longitudinal and two of circumferential direction, respectively, were performed using the EUS 40 testing machine. The DDA 50 - EU strain gauge with $\mathrm{L}_{\mathrm{o}}=85 \mathrm{~mm}$ was used to measuring the deformations. In a similar way, impact bend tests at $0{ }^{\circ} \mathrm{C}$ were performed at both directions, by three specimens each, using the PSWO 30 impact testing machine.
The measured values comply with those of 11353 steel. Their mean values are given in Table 2 .

After the mechanical tests have been performed, the pipeline sections with repair patches were welded together to one pressure body - Figure 4 . Both ends were blinded with bottoms. In the surroundings of patches, the thickness of the tube wall was measured in nodal points of the network of $100 \times 100 \mathrm{~mm}$. In the surroundings of patch $\mathrm{A}$, the lowest value of the wall thickness was $7.01 \mathrm{~mm}$ and the highest one was $9.09 \mathrm{~mm}$. In case of patch $\mathrm{B}$, the lowest and highest values were $6.81 \mathrm{~mm}$ and $8.89 \mathrm{~mm}$, respectively. Considerable differences in the wall thickness were quite apparent.

Prior to the full scale hydrostatic burst tests, the patches were equipped with strain gauges by means of which the local deformations were measured during the test. The arrangement of strain gauges and the strain values evaluated as dependent on pressure during the full scale test are shown in Figures 5 and 7 (patch A), and in Figures 6 and 8 (patch B), respectively.

In the case of the repair patch $\mathrm{A}$, six strain gauges were used - Figure 5, two of them oriented longitudinally (strain gauge 13 situated in the centre of the repair patch $\mathrm{A}$ and strain gauge 17 distant $200 \mathrm{~mm}$ from the centre of the repair patch $\mathrm{A}$ in the longitudinal direction). Three strain gauges were oriented in the circumferential direction (strain gauge 12 situated in the centre of 


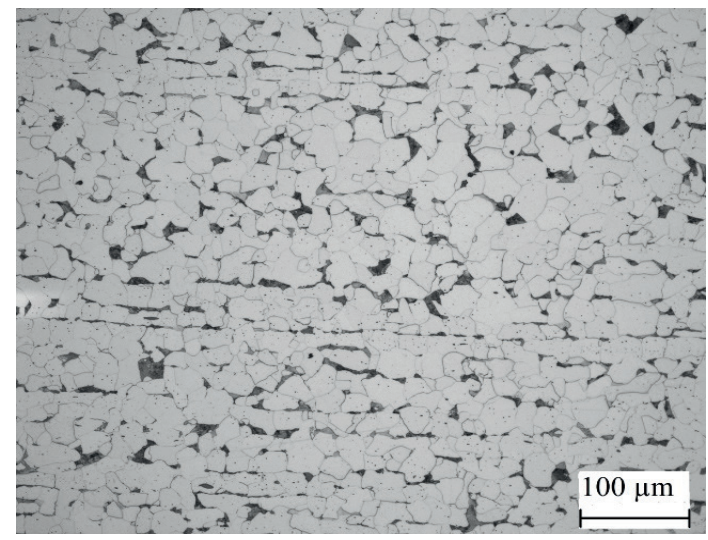

Figure 3 Ferrite-pearlite microstructure of the pipe

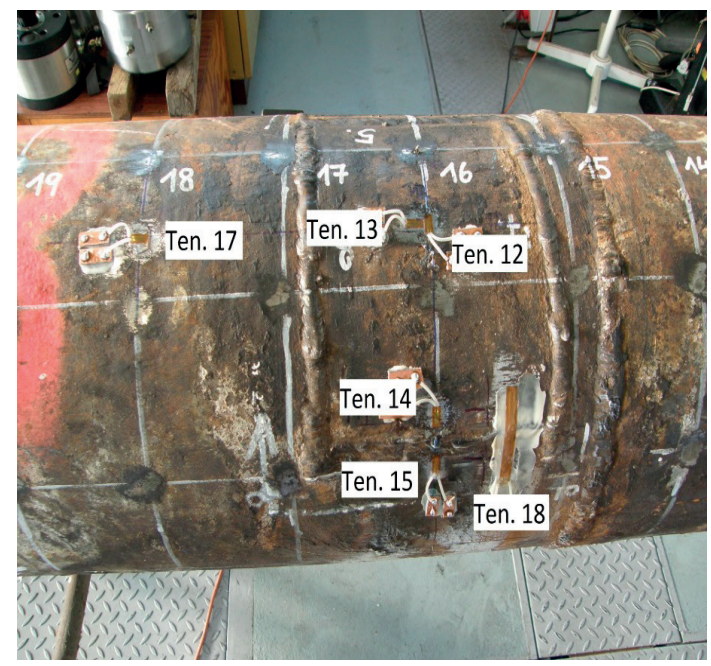

Figure 5 Gage location on repair patch $A$

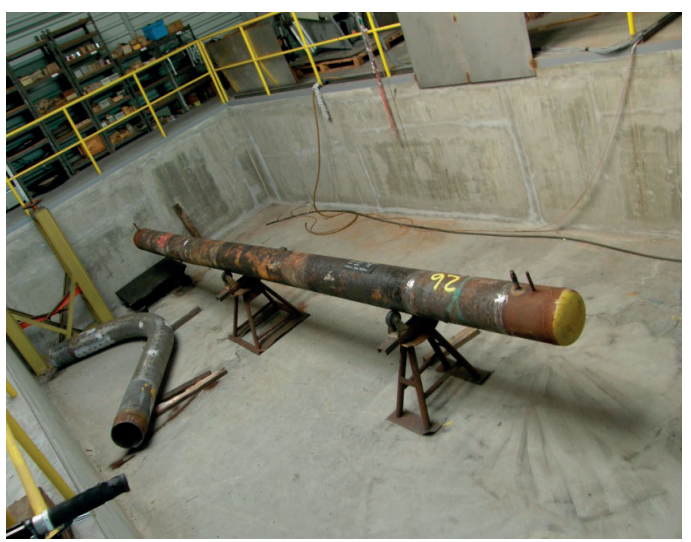

Figure 4 Pipeline with two types of welded repair patches

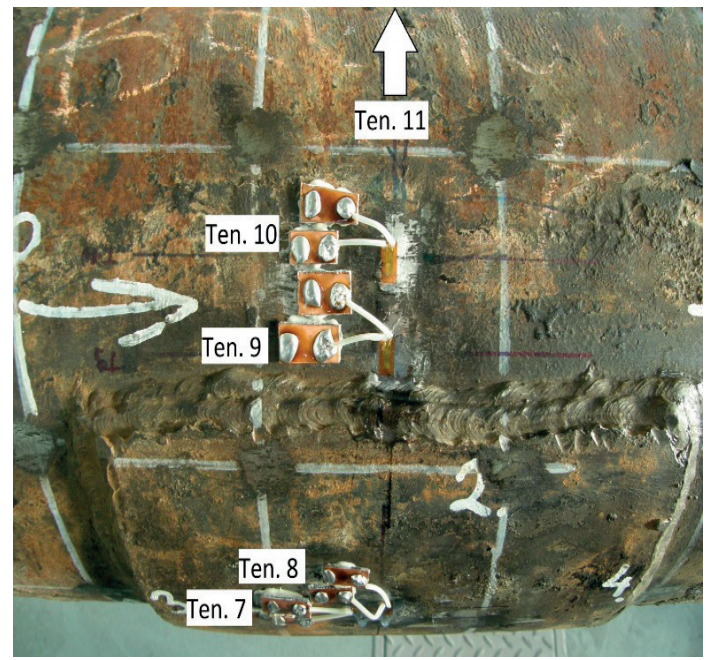

Figure 6 Gage location on repair patch $B$ the repair patch $\mathrm{A}$, strain gauge 14 placed near the weld in which - according to NDT inspection - a lack of root fusion occurred along its whole length). Strain gauge 15 was situated also near the weld, but it was placed at the tube side. Special, very long strain gauge of the base length $50 \mathrm{~mm}$ was bonded across the whole weld.

For measurement of the deformation of the repair patch B, five strain gauges were applied - Figure 6. Four strain gauges were oriented circumferentially, one of them was used for measurement of the circumferential strain in the centre of the patch $\mathrm{B}$ (strain gauge 8 ), the remaining three were situated on the tube wall (strain gauges 9, 10, 11). One strain gauge was oriented longitudinally and was placed in the centre of the patch B.

The body equipped with strain gauges was first tested by 10000 pressure cycles. The cyclic loading asymmetry approached to $\mathrm{R}=0$, maximum pressure approached to the operational one $\mathrm{p}_{\max }=6.3 \mathrm{MPa}$. During the first cycle, values from all the strain gauges were continuously recorded. All strain gauges showed linear dependencies of deformation on pressure and only very small residual deformations were observed after the unloading. The residual deformations were likely caused by some initial setting of the body on the supports. Analogous measurements of residual deformation were carried out at regular intervals after specific number of cycles. Fluctuation of deformations after 10000 cycles is the same for all strain gauges. The changes arose rather from the temperature dilatations than from the real plastic deformation.

The full scale hydrostatic burst test was carried out with continuous measurement of deformations and one planned dwell at the yield point with regard to the biaxial state of stress $\mathrm{p}_{\text {бy }}=16.8 \mathrm{MPa}$. The increase of deformation in both repair patches was linear up to $15.5 \mathrm{MPa}$. After that, a rapid increase of deformation occurred (see Figures 7 and 8). Destruction occurred at $19 \mathrm{MPa}$ in the repair patch $\mathrm{B}$, which was overlapped. The reached stress value $19 \mathrm{MPa}$ was at least three times higher than the operational one. It was shown that in this specific case this type of repair ensured quite a good safety level. 


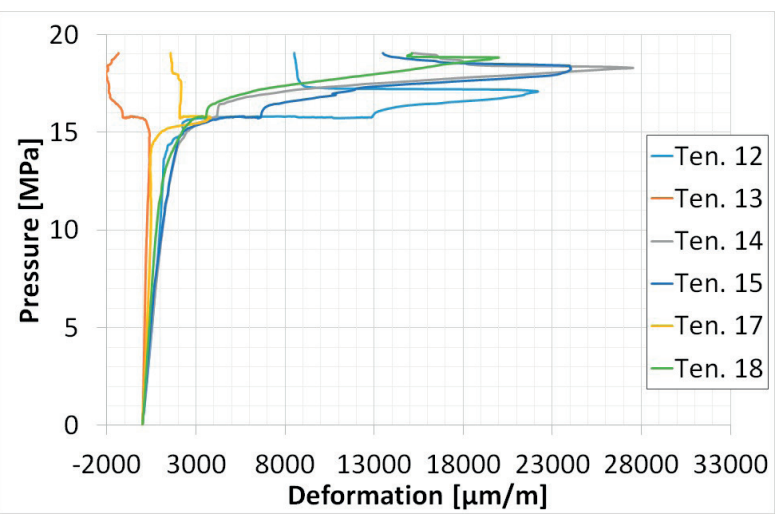

Figure 7 Dependency of pressure on deformation of the patch $A$

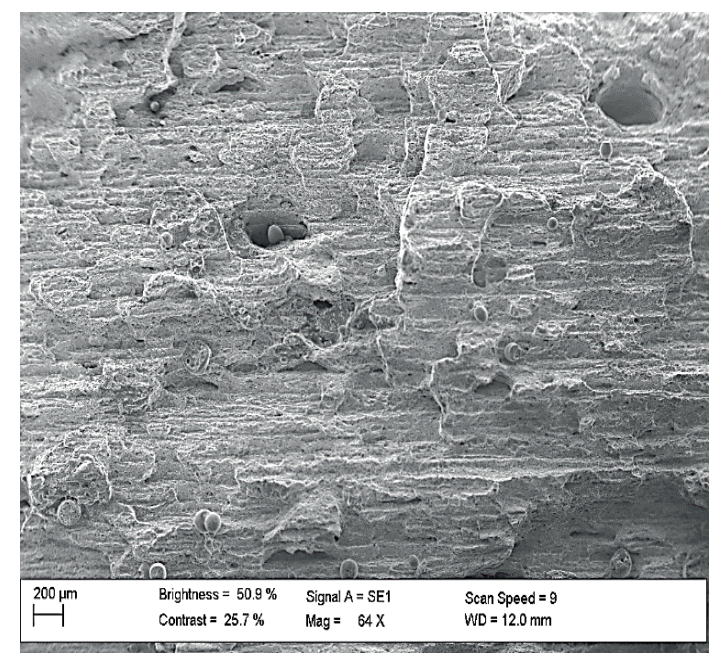

Figure 9 Woody fracture

Area of the fracture initiation was cut out and investigated by means of the Zeiss EVO MA 10 scanning electron microscope. Failure initiation occurred at the fusion zone which represented the boundary between the weld and the heat affected zone and formed a notch effect in the structure. No structural defects (pores, cracks, inclusions) were found inside the area of failure initiation. The fracture type can be classified as woody fracture that occurs in wrought steels in connection with a bad metallurgical quality (Figure 9). It is known in general that woody fracture can be related to row-like structure, inhomogeneities in phosphorus and sulphur contents, presence of gas bubbles or hydrogen [11]. A more detailed analysis of the woody fracture revealed its dimple morphology (see Figure 10). In areas more distant from the fracture initiation, the shear fracture prevailed.

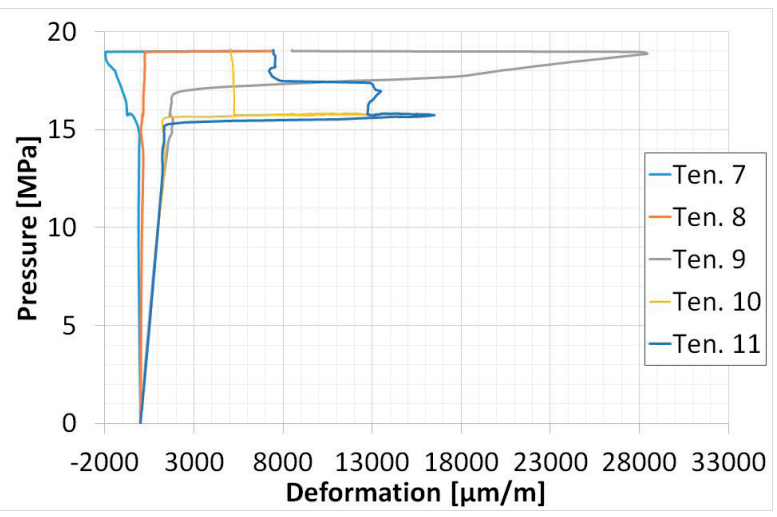

Figure 8 Dependency of pressure on deformation of the patch $B$

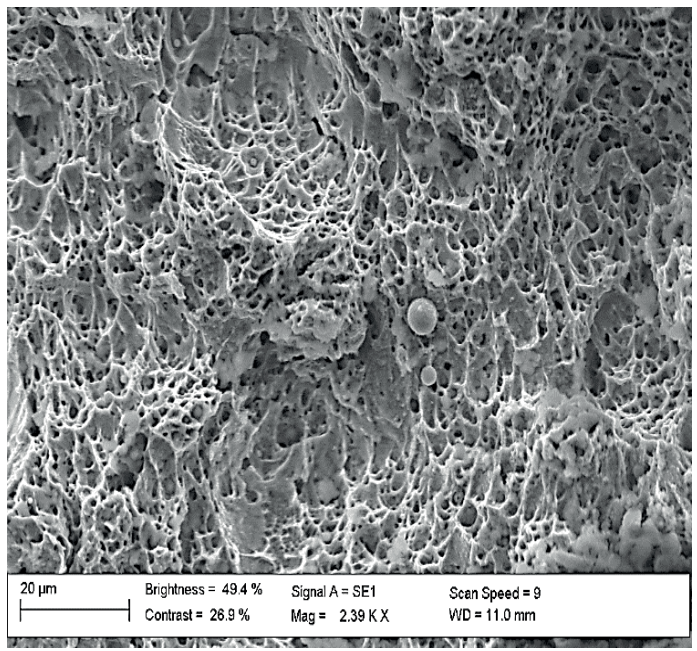

Figure 10 Dimple morphology of woody fracture

\section{Conclusions}

An extensive experimental programme aimed at evaluation of the effect of repair patches welded into the pipe wall during the gas pipeline repairs on pipeline integrity, strength and resistance to pressure cycles, was carried out. Limit states, safety and reliability of the pipeline with repairs made by the "welding-on" procedure were evaluated. In this specific case of the repairs, failure occurred at a pressure three times higher than the maximum service pressure. The failure of the tested pipeline section actually occurred in the repair patch, namely the patch $\mathrm{B}$, which was an overlapping patch. This was a fairly unexpected result, because according to the NDT inspection, a fairly worse quality was indicated in the case of the single patch, just welded into the wall, not overlapped. 


\section{KOMNIKCCle}

\section{References}

[1] ZHAO, Y., SONG, M.: Failure Analysis of a Natural Gas Pipeline. Engineering Failure Analysis, 63, 61-71, 2016.

[2] LINHART, V., CERNY, I., HORALEK, V.: Destruction of a Gas Pipe after a Long Time of Operation in the Karlovy Vary Area. Plyn, 91(6), 129-131, 2011.

[3] CHOUCHAOUI, B. A., PICK, R. J.: Behaviour of Longitudinally Aligned Corrosion Pits. International Journal of Pressure Vessels and Piping, 67(1), 17-35, 1996.

[4] LEE, Y. K., KIM, Y., MOON, M. W., BANG, W., OH, K., KIM, W.: The Prediction of Failure Pressure of Gas Pipeline with Multi Corroded Region. Materials Science Forum, 475, 3323-3326, 2005.

[5] CERNY, I., LINHART, V.: An evaluation of the Resistance of Pipeline Steels to Initiation and Early Growth of Stress Corrosion Cracks. Engineering Fracture Mechanics, 71(4-6), 913-921, 2004.

[6] MOUSTABCHIR, H., AZARI, Z., HARIRI, S., DMYTRAKH, I.: Experimental and Numerical Study of Stress-Strain State of Pressurised Cylindrical Shells with External Defects. Engineering Failure Analysis, 17(2), 506-514, 2010.

[7] CERNY, I., SIS, J.: Experimental Assessment of Residual Fatigue Life of High Pressure Pipeline Section Containing Longitudinal Cracks. Key Engineering Materials, 713, 163-166, 2016.

[8] OTEGUI, J. L, URQUIZA, S., RIVAS, A., TRUNZO, A.: Local Collapse of Gas Pipelines under Sleeve Repairs. International Journal of Pressure Vessels and Piping, 77(9), 555-566, 2000.

[9] FAZZINY, P., OTEGUI, J.: Influence of Old Rectangular Repair Patches on the Burst Pressure of a Gas Pipeline. International Journal of Pressure Vessels and Piping, 83(1), 27-34, 2006.

[10] EN ISO 643. Steels - Micrographic Determination of the Apparent Grain Size. European Committee for Standardization, 2014.

[11] KOUTSKY, J., JANDOS, F., KAREL, V.: Fractures of steel parts/Lomy ocelovych casti (in Czech). SNTL, 1976. 